\title{
Brian Noonan, Dianne Hallman, and Murray Scharf (Eds.) A History of Education in Saskatchewan: Selected Readings.
}

Regina: Canadian Plains Research Center, University of Regina, 2006. 235 pp.

\section{John Calam}

Since the time of Alexander Pope (1688-1744) whose Dunciad alleged that indiscriminate studies "stuffed the head / With all such reading as was never read," editors of collected essays in education have published at some risk. To be sure, editorial dexterity and authorial clout sometimes lent the better specimens of this genre the intellectual allure and contextual fit they deserved. Their less persuasive counterparts, alas, were more frequently written off in academe as exercises in butterfly-catching, lucky dips, or additives to students' lecture notes. Mercifully, no such detractions apply to A History of Education in Saskatchewan.

In this last respect, editors and contributors alike resist the urge to ride madly off in all directions. Stemming from a University of Saskatchewan anniversary conference, this volume emerges as a selection winnowed to "three natural themes," notably, building the state; schooling and culture; and teachers and teaching. Authors enjoy a comfortable division of labour. Similarly, an introduction, sectional prefaces, bountiful endnotes, information on contributors, a bibliography, and a workable index unite to assist readers in navigating the main text and familiarizing themselves with associated scholarship. Other such consolidating factors include the currency of educational issues at stake and a marked revisionist thrust throughout. As well, writers conceive of Saskatchewan's educational challenges as resonating both Canadawide and internationally.

Within this framework, Murray Scharf's historical overview deals adroitly with relevant educational legislation, its promulgators, and a disparate rural population intimately acquainted with environmental, economic, ethnic, religious, and linguistic realities. In the same sense, Brian Noonan's thorough account of Saskatchewan 
separate schools helps untangle the historic snarl of language and religion affecting their evolution. In his penetrating study, Michael Owen emphasizes the political tension separating Saskatchewan residents who pushed for larger school units on the grounds of fiscal economy and enhanced educational opportunity, from others who believed such a move would jeopardize their local influence and power. And, with commendable economy, John Lyons tells of Henry Janzen and curricular reform in a province whose educational resources once failed to match the worst consequences of drought, depression, minimally prepared itinerant teachers, and chronic misreading of Aboriginal heritage.

Concerning classroom learning, Catherine Littlejohn offers a tightly argued analysis of schooling for Saskatchewan's First Nations and Metis children and the "cultural destruction" they sustained as a result. Throughout his compelling enquiry into government legislation and policy as it affected francophone instruction, Wilfrid Denis persuasively argues the insufficiency of francophone instruction wrenched from its cultural matrix. Cameron Milner delivers an arresting account of Valley Christian Academy which in collaboration with the Saskatchewan Valley [Public] School Division created "greater assimilation of a ... [Mennonite] minority group than had occurred when [its] students ... were part of existing public schools.” John Lyons and Margaret Lyons deftly recapitulate the early years of the Saskatchewan Arts Board and trace the work of Executive Secretary Norah McCullough whose prior experience overseas and with Canada's National Gallery inspired her crusade for the best in fine arts, architecture, and handicrafts in the lives of all Canadians. And with precision and affection, Cathy Holtslander presents a cameo of Annie Hollis whose suffragist origins, farm life, rural teaching experience, and political activism converged to ameliorate "the welfare of the human family."

In the matter of teachers and teaching, Dianne Hallman reminds the reader that in 2003 women formed 68.3 percent of Saskatchewan's teaching cadre, a ratio little altered since 1928. From this simple statistic flows her graceful albeit critical biographical rendition of professional feminization based on word-of-mouth testimony. Complementary to this theme is June Corman's meticulous account of transiency among south Saskatchewan women teachers enduring the primitive conditions of their one-room schools, taxing workloads, disciplinary pressures, daunting living arrangements, and fragile social relationships - hardships alleviated nonetheless by the "relative ease" during teacher shortages of their seeking improved conditions elsewhere. In contrast, Verna Gallén's comprehensive submission deals with a teacher organization - the Saskatchewan Teachers' Federation-which over the years worked untiringly toward a profession in tune with "the cultures and traditions of Saskatchewan people." Following their striking reflection that the measure of a society's quality and maturity is the treatment afforded its "most vulnerable citizens," Robert Sanche and Harry Dahl trace the development of Saskatchewan's education policy from its origins in segregation, through schools "dedicated" to particular disabilities, to eventual integration in community schools. Enjoying the last word, Sam Robinson sets in historical context Saskatchewan's core curriculum of the 1980s. The latter he explains as having resulted not only from government initiatives but also 
from widespread public and professional consultation in aid of first-rate education relevant to the future needs of all children.

Here, then, is a volume faithful to its central objective — presenting "a collection of voices." Casual readers will find it richly evocative of their own educational experiences on Canada's Great Plains or their rural equivalents elsewhere. Seasoned scholars will appreciate its heuristic qualities. School boards and their administrators will find much within its pages testifying to the perils of their endeavours given the complexity of parents' expectations as to what their public schools are for. Practising teachers will identify numerous points of entry into their current professional concerns. And between its covers teachers-to-be may well discover confirmation of the central task ahead - service to the children of a vast and socially complex land.

Read and enjoy! 